\title{
Основы материальной культуры горцев Военного времени (оружие и оборонительные сооружения)
}

\begin{abstract}
Аннотация. На основе малоиспользуемых архивных и документальных материалов в статье анализируетсл роль материальной культуры гориев Военного времени (ХIII - ХVIII вв.), представленной оружием и оборонительными сооружениями. Доказывается, что все кавказские народы продумали четкую систему зашить от нападений не только внешних врагов, но и свочх соплеменников, поошрявшихся к набегам феодальной верхушкой, нуждой, личной удалью. Поэтому нет на Кавказе почти ни одного селения, над строениями которого не доминировали бы боевые или жилье башни, а на прилегаюшей территории имелись заградительные стены и таможеннъе заставы, пещерные (скальные) укрепления и крепости, комплексъ замкового типа. Методологическал база статьи была сформирована за счет историко-сравнительного, структурного, абстрактно-логического методов исследования. Каждый из них имел свою область применения и сыграл важную роль в обработке, систематизачии и обобщении исследуемого материала. Так, историко-сравнительный метод позволил проанализировать сопоставимзе факты и на этой основе вылвить как закономерности, так и особенности вылвления материальной культуры гориев времен Военного времени, представленного фортификационными сооружениями и оружием всех видов. Метод структурного анализа был необходим для изучения сложных структурных компонентов, не расчленяя их на отдельные составляюшие элементы. Абстрактно-логический метод представил возможность обобщения, синтеза и интеграиии выводов по теме статьи в челом. Делаются выводъ, ито сама фортификачионная культура кавказских народностей имела своей особенностью генетическую связь с эмпирикой жилишного строительства и потому являла собой все позитивные достижения этнического зодчества. Она своей созидательной деятельностью, красочно отразилась в памятниках истории и культуры населявших край народов.
\end{abstract}

Ключевые слова: боевые башни, горские народъ Кавказа, северокавказский край, созидательная деятельность, пещерные укрепления, фортификачионная культура, этническое зодчество, Жилищное строительство, Строительные технологии, Монументальные сооружения.

Abstract. Based on rarely used archival and document material, this article analyzes the role of Highlanders material culture of the Wartime (13th-17th centuries), represented by armory and fortifications. This article states that all Caucasian nations developed a clear defense system against foreign enemies and fellow tribesmen alike, who were raid driven by feudal elites, need or personal bravado. Therefore, there are almost no settlements in the Caucasus region, where turrets or habitable towers did not overlook the buildings and surrounding grounds did not have defense walls, customs posts, cave covers, fortresses or castlelike complexes. Methodological basis for this article was formed by historical and comparative, structural, abstract and logical research methods. Each of them had a particular application and played a significant part in processing, systematization and generalization of studied sources. Specifically, historical and comparative method allowed to analyze the facts under comparison and thereupon define both consistent patterns and characteristics of discovering Highlander material culture of the Wartime, represented by fortifications and armory of all kind. Structural analysis method was necessary for a study of complex structural components without dividing them into elements. Abstract and logical method allowed generalization, synthesis and integration of article's conclusions. The author concludes that the fortification culture was defined by the genetic ties to the empirics of house building and therefore contained all the positive achievements of ethnic architecture. Its workmanship was beautifully reflected in historical and cultural landmarks created by the nations who inhabited this region.

Key words: turrets, highland people of the Caucasus, North Caucasus country, workmanship, cave covers, fortification culture, ethnic architecture, house building, construction technologies, monumental building. 


\section{Исторический журнал: научные исследования № 4 (34) • 2016}

DOI: 10.7256/2222-1972.2016.4.19644

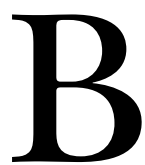

ведение. Начиная с XIII и вплоть до XVIII века включительно, в истории всех северокавказских народов наблюдается коренная трансформация этнической карты региона, обусловленная в первую очередь, мощными внешнеполитическими и глубокими социально-экономическими факторами. К ним относятся агрессивные устремления заморских владетелей Турции, Крыма и Ирана, нашествие татар, завоевания Тимура, экспансия ногайских орд, пришествие адыгских народов, установивших контроль над обитателями горских территорий Центрального Предкавказья, межплеменная рознь и внутренние смуты самих кавказцев, порожденные борьбой за власть. Все это становится основной сутью кавказской политики, построенной на диктате сильных, порабощении и истреблении слабых. В этих условиях у горцев настоятельно возникала необходимость создания разнообразных оборонительных сооружений, предназначенных для защиты жизни и имущества как отдельных семей, так и целых обществ.

Обсуждение. Сама фортификационная культура кавказских народностей имела своей особенностью генетическую связь с эмпирикой жилищного строительства и потому являла собой все позитивные достижения этнического зодчества. Прежде всего она была представлена обилием оборонительных памятников, сосредоточенных в Южной и Северной Осетии, Чечне и Ингушетии, Балкарии и Карачае, Дагестане и Грузии. Некоторые из них возводились еще в глубоком средневековье, потому сами автохтонные народы на протяжении столетий следили (по возможности) за их состоянием, время от времени подновляя и продолжая использовать в военных целях. Согласно сведениям арабских авторов, в Серире, Лакзе, Хамзине и др. «царствах» имелись крепости или замки. До нас дошло описание (Х в.) одного из «замков» царя Серира, сделанное путешественником Ибн Русте: «Этот замок находится на вершине горы, он имеет четыре фарсага в длину и столько же в ширину и окружает его стена из камня» [1, с.42-47]. Большие размеры замка позволяют заключить, что речь идет о целой системе оборонительных сооружений.

Одним из замечательных памятников периода раннего средневековья являлись дербентские сооружения, состоящие из нескольких параллельно идущих стен. Они запирали Дербентский проход с запада на восток. Одним своим краем стены уходили в морской залив, где образовали своеобразную гавань, закрытою горной цепью. Эти укрепления вместе с многокилометровой цепью оборонительных сооружений составили единый комплекс защиты со стороны гор.

До нас дошли различные описания строительной технологии дербентских фортификационных сооружений, оставленные арабскими историками. Так, Ибн-ал-Факих свидетельствовал о знаменитой стене дербентской, которая была представлена тесаными камнями четырехугольной формы, скрепленными между собой железными болтами. Автор восторгается фортификационным искусством горцев, так как «пять десятков человек не могли приподнять один такой камень». Путешественник Хиляс ас-Саби обращает внимание на воротах из железа и стене, в которой располагались в симметричном порядке камни, в каждом из которых имелось по два отверстия для нахождения железной палки, облитой свинцом» [2, л. 6-12].

Монументальные сооружения Дербента продукт не одного года и не одного десятилетия. Они неоднократно разрушались. В строительстве этих укреплений участвовали многие кавказские народы. Об этом факте свидетельствует Моисей Каганкатваци: «...персидские цари на строительстве дербентских стен изнурили страну нашу, собирая архитекторов и изыскивая разные материалы» [3, с.15]. В архитектуре дербенских зданий воплотились лучшие строительные традиции северокавказских горцев.

Остальная часть упомянутых сооружений появилась уже в послемонгольский период и связана с историей конкретных этносов и различных социальных групп населения. Так, были построены крепости и замки в 1241 г. в агульском сел. Рича, в лезгинском селе Ахты, в XVI - XV вв. в устье р. Годлик на Черноморском побережье, в 1432 г. в сел. Цахур в Южном Дагестане, в 14431446 гг. в гор. Тамани, в 1519 г. в гор. Темрюке, в 1369 г. в даргинском сел. Муги, в XIV в. в лезгинском сел. Хоредж, в XVI в. в даргинском сел. Ицари [4, с.180-184] и др.

Северокавказские народы продумали четкую систему защиты от нападений не только пришлых издалека врагов, но и своих соплеменников, поощрявшихся к набегам феодалами, нуждой, личной удалью. Поэтому нет на Кавказе почти ни одного селения, над строениями которого не доминировали бы боевые или жилые башни. Пещеры и скальные гроты использовались для создания как простейших по своей архитектуре 
укреплений, так и настоящих крепостей (Нузал, Урсмдон, Дзивгис). На подступах к поселениям, на удобных для наблюдения высотах, сооружались сторожевые башни: с них дозорные передавали сигнал тревоги односельчанам. В ряде стратегически важных мест ущелья перегораживались заградительными стенами и заставами, защищавшими перевальные пути в Закавказье. Таким образом, все фортификационные сооружения Кавказа можно классифицировать следующим образом: заградительные стены и таможенные заставы, пещерные (скальные) укрепления и крепости, комплексы замкового типа («галуаны» - осет., «г1ал» - кубач., «къали» дарг., «квал»-лезг., «галай-чуэ»- инг.), боевые, жилые и полубоевые башни.

Следует отметить, что в данной статье мы не рассматриваем проблемы строительства горского жилища, поскольку это в известной мере выходит за рамки исследуемой тематики. Здесь же отметим, что обыкновенно фортификационные сооружения располагались в комплексе с бытовыми и жилыми постройками, которые так же были приспособлены для оборонительных нужд.

Говоря о башенных сооружениях гордого Кавказа, проф. Г.А.Кокиев неоднократно подчеркивал, что возникли они на почве одинаковых социально-экономических условий, в которых, по-видимому, находилось на протяжении веков большинство кавказских горцев. Он же впервые выдвинул тезис о том, что внутри общекавказской строительной культуры башенных построек имеются свои чисто национальные (локальные) отличительные признаки. Данный тезис представляется особенно важным, поскольку, по словам исследователя, «ни в чем не выражается так полно душа народа, как в созданиях его искусства. Народ может заимствовать у соседей орудия для разных работ, научные сведения, политические и общественные установления. Но искусство всегда национально. Даже подражая, народ берет из чужих произведений то, что отвечает его вкусу, его уровню развития», он создает творения, живущие веками» [5, с.87]. Этот тезис был впоследствии развит Е.И.Крупновым [6, с. 123], В.И.Марковиным [7, с.243], Н.Е.Урушадзе [8, с.54-70], И.М. Мизиевым [9, с.17], М.Б.Мужухоевым [10, с.94-106], А.Ф. Гольдштейном [11, с.212] и другими исследователями, изучавшими материальную и духовную культуру горцев.

Вместе с тем невозможно не обратить внимания на то, что сходных черт в архитектуре ба- шенных построек горного Кавказа выявлено отнюдь не меньше, чем отличительных и поэтому часто встречающиеся в современной научной литературе рассуждения о самобытности (уникальности) тех или иных разновидностей интересующих нас памятников нуждаются в более строгой аргументации. По справедливому замечанию исследователя С.О.Хан-Магомедова, национальные особенности архитектуры должны прежде всего «гармонично сочетаться с удовлетворением материальных потребностей народа, правильным учетом природно-климатических и бытовых местных условий, достижениями строительной техники»и әстетическими идеалами. Будучи присущими архитектуре конкретного народа, особенности эти отражают и психический его склад» [12, с.169-170]. В то же время, как уже говорилось, в культуре любого народа проявляются и интернациональные (общечеловеческие) черты, сближающие ее с культурой других этносов, и именно они в силу целого ряда исторических и прочих условий получают преимущественное развитие. В свете высказанных положений мы и хотели бы остановиться несколько подробнее на общих закономерностях развития башенной архитектуры, на том, что объединяет, а не разъединяет культуры кавказских народов, хотя в ходе изложения нам придется высветить и некоторые частные (локальные) вопросы.

Специфичность архитектурных строений у всех кавказских народностей заключалась в её конструктивности, простоте природных строительных материалов, умелом использовании последних зодчими, научившимися создавать из них своеобразные сооружения. Вековая монументальность и способность воздействия на людей обусловливались структурной логичностью построек и применяемыми к ним конструктивными решениями. Издали стены боевых башен воспринимались несокрушимым монолитом, вблизи это впечатление еще более усиливалось, ибо упрятанные в каменную твердь и почти неразличимые извне бойницы не нарушали целостности восприятия, не разрывали кладку на части. Этот факт отмечал осетинский поэт Юрий Боциев в поэме «Город на Тереке»:

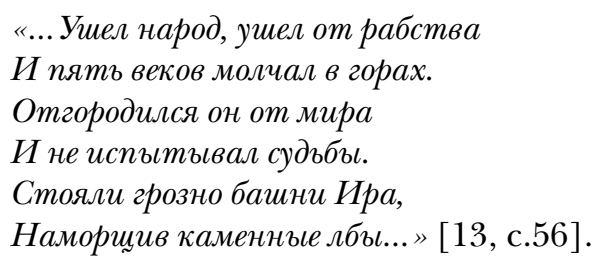

И пать веков молчал в горах.

Отгородился он от мира

И не испьтывал судъбъ.

Наморщив каменнъе лбъ...» [13, с.56]. 


\section{Исторический журнал: научные исследования № 4 (34) • 2016}

DOI: $10.7256 / 2222-1972.2016 .4 .19644$

Право сооружать боевые башни принадлежало исключительно знатным («сильным») родам или фамилиям. Зависимым от феодалов родам на постройку башни требовалось особое разрешение, которое можно было получить у владетелей на определенных условиях.

Нижний этаж боевых башен использовался как хозяйственное помещение или как камера для пленников, но зачастую он засыпался землей и камнями, чтобы создать дополнительные трудности в случае осады неприятелем. Единственный вход в башню устраивался на уровне второго яруса. Стены абсолютного большинства боевых башен прорезаны узкими бойницами, над ними были сделаны навесные балкончики машикули, которые предохраняли от попадания шальной пули.

Говоря об особенностях башенных построек Северного Кавказа, необходимо отметить, что почти все осетинские и частично чеченские башни были плоскокровельными и этим они напоминали аналогичные сооружения Грузии. Однако в самой Грузии и соседней с ней Балкарии строились башни с двухскатными кровлями.

В фольклоре кавказских народов в той или иной степени отразились предания о строительстве оборонительных сооружений. Возведение их сопровождалось разными по своему характеру обрядами (в зависимости от вероисповедания), которые, по представлениям наших предков, должны были обеспечить неприкосновенность жилища и всего, что в нем находится. С сожалением приходится констатировать, что часть этих фольклорных источников не сохранилась до наших дней, однако, учитывая культурно-историческую близость кавказских народов, можно с известной осторожностью экстраполировать содержащиеся в их эпосе, сказках, исторических песнях сведения на определенные явления, имевшие место в реальной действительности. Ниже мы приводим сокращенный вариант вайнахской песни о строительстве боевой башни - воув, поскольку она, на наш взгляд, в полной мере отражает не только производственный процесс, но и социально-идеологические представления северокавказских горцев независимо от их этнической принадлежности:

\footnotetext{
«... Триждъ землю поили молоком, трижды срывали грунт,

И только когда земля отказалась пить, положили первые камни;
}

Восемь огромнъцх гльб, образуюших угль воув,

Ибылкаждый камень иеноюравен быку, а весомвосъми бъкам.

Их привезли с вершинь горы, взявши из-под голубого льда...

Каждый камень везли двенадиать быков, ломая копыта от напряженья,

Каждый камень тесали двенадиать дней четъре камнетеса,

И стальные тесла крошились у них, будто сделанные из липьк...

Двадиать тесел каждый каменотес сломал о ребра камней,

И камни стали ровны, как стекло, и приняли нужный вид!..

Тогда четыре, как горы, седъх старика осмотрели и ошупали их,

И каждый сказал: “Теперь хороши, ни порока, ни трещинъ нет!»

Икаждый сказал: «Воув будет крепка, как наши горы крепки,

И будет стоять во веки веков, как мир во веки веков стоит!..»

И каждый сказал: “Мь землю здесь поили густым молоком,

А камни эти, чтоб были крепки, напоим горячей кровъю, -

Пусть свяжет кровь четьре уала, как род наш кровъю связан,

И этой связи не сокрушат ни смерть, ни вечное время!» [14, с.23-25].

Подавляющее большинство обследованных специалистами северокавказских боевых зданий автономно от их вида и форм перекрытия обладало механизмами огневого, а не лучного сражения. Машикули башен являли собой небольшие сквозные проёмы (гаплоидные, бинарные, а кое-когда и триплётные), установленные в специально приготовленных для этого углублениях (нишах), количеством от 3 до 6 на каждом ярусе. Помещались они с учетом абсолютного обзора ближайшей к башне территории и обладали самым разнообразным направлением, зачастую движением вниз или в сторону. «Габариты амбразур были настолько маленькие, что они при всем желании не вместили бы плечо стрелка-лучника», как то предполагал Х.Д.Ошаев [15, c. 75]. Для лучшего боя в старину устраивались амбразуры пошире; засвидетельствованы они в нескольких сооружениях Грузии, Дагестана и Осетии. Аналогичных бойниц в башнях Чечни и Ингушетии пока не обнаружено, ибо здесь было 


\section{Культурное наследие - памятники истории и культуры}

DOI: $10.7256 / 2222-1972.2016 .4 .19644$

обыкновением вести обстрел из луков, находясь на самой высокой боевой площадке.

Как считают исследователи (Е.Крупнов, П.Закарая, В.Виноградов, Д.Чахкиев, Р.Даутова, В.Калинкин и др.), появление оконных амбразур, предназначенных для огневого боя, объективно было связано с распространением на Северном Кавказе огнестрельного оружия (в XVI - первой трети XVII в.), хотя первое знакомство с ним, несомненно, произошло у горцев гораздо раныше. По крайней мере, по грузинским источникам нам известно, уже в 1488 году осадившие Коджорскую крепость иранские войска «стреляли из ружья»; в 1536 году в междоусобных войнах имеритинских феодалов вооруженные "ружьями и большими пушками» турки оказывают помощь одной из группировок; в конце XVI столетия огнестрельное оружие имелось и у грузинского войска. В начале XVII века русские путешественники, следующие через Ингушетию в Грузию, заметили у «горских и турских людей пищали и луки, и сабли, и копье» $[16$, с.176]. Этот же факт подтверждают в 1604 году русские послы, которые жаловались, что их окружили горские люди с огненным боем...» и называли этих лихих людей калганцами (т.е. ингушами - Н.Б.), спустившимися с гор. Любопытно, что и в дигорских мистических преданиях о Баделе, датируемых рубежом XV XVI веков, упоминается ружье, наводящее «панический страх на врага» [17, с.17-23].

Мы не знаем, какие именно системы огнестрельного оружия бытовали у горцев до превращения их в так называемые «горские ружья» XVII - XVIII столетий, но то, что они сосуществовали с луками и стрелами, ни у кого сомнений не вызывает. Бесспорен и тот факт, что последние являлись отмирающим (пусть медленно, но неуклонно) видом вооружения, которое уже не могло существенно повлиять на архитектуру башен «периода расцвета строительства» (по В.И.Марковину [18, с.244]). Напротив, горцам приходилось учитывать новые веяния в фортификационном искусстве, вооружаться и быть готовыми к отражению любой агрессии.

Помимо стрелкового оружия у кавказцев обычным вооружением были кинжал и сабля. Широко использовались ими также копья, луки, секиры, пращи и др. При защите тела от них использовались кольчуги, шлемы, щиты, панцири, которые генетически перешли от алан и сохранились у них до наших дней. Так, еще в первой половине XIX в. Ю.Клапрот, посетивший осетин, проживающих в верховьях р. Терек, писал, что они «пользуются еще щитами овальной формы, сделанными из твердой кожи или дерева и снабженными железными обручами и головками гвоздей; длина его редко превышает 1 фут» [19, с.112]. Стрельба из лука, широко известная у горцев, вошла позже в состав детских игр, и бытует до сих пор в горах Осетии.

Заключение. Суммируя всё вышеизложенное, мы приходим к выводу, что эпоха подъема северокавказского архитектурного строительства пришлась на XVI - XVII столетия (и отчасти затронула XVIII миллениум), а не на XV XVII века, как о том писал известный археолог В.И.Марковин. Думается, к этому сроку относится появление и полубоевых башен, синтезировавших в себе сходство с жилыми и боевыми башнями и основной массы гулуанов - замков, содержащих обе модели построек. Но это, естественно, не умаляет тот факт, что в Северокавказском крае не было более древних замковых ансамблей, мы просто в данной статье отмечаем те из них, которые обозначились во времена стрелкового оружия, характеризовавшиеся феодальными смутами, раздробленностью горских обществ, противостоянием вражеским нашествиям и, не смотря ни на что, - созидательной деятельностью, красочно отразившееся в материальных памятниках истории и культуры населявших край народов.

\section{Библиография:}

1. Ибн Русте. Из книги драгоценных камней. Пер. с арабского Н.Караулова //СмОМПК, № 32, 1903.-С. 42-47.

2. Пахомов Е.А. Крупнейшие памятники Сасанидского строительства в Закавказье //СА. № 8. 1946.-С. 13-19.

3. Каганкатваци М. История Агван.-СПб., 1861. С. 15.

4. Лавров Л.И. Эпиграфические памятники Северного Кавказа на арабском, персидском и турецком языках.-М., 1980. C. 74.

5. Кокиев Г.А. Боевые башни и заградительные стены горной Осетии //ИЮОНИИ.-Сталинир, 1935.-Т. 2. С. 87.

6. Крупнов Е.Н. Средневековая Ингушетия.-М.: Наука, 1971. С. 123.

7. Марковин В.И. Дорогами и тропами Дагестана.-М.: Искусство, 1976. С. 243.

8. Урушадзе Н.Е. К семантике прикладного искусства древнего Кавказа и Закавказья //СА, 1979. № 1.-С. 54-70.

9. Мизиев И.М. Чеченские средневековые памятники в верховьях р. Чанты-Аргуна //Древности Чечено-Ингушетии. М.:Наука, 1963. 423 с. 


\title{
Исторический журнал: научные исследования № 4 (34) • 2016
}

\author{
DOI: $10.7256 / 2222-1972.2016 .4 .19644$
}

10. Мужухоев М.Б. К истории позднесредневекового зодчества Центрального Кавказа //Поселения и жилища народов Чечено-Ингушетии. Грозный, 1984. 467 с.

11. Гольдштейн А.Ф. Башни в горах.-М.: Советский художник, 1977. 523 с.

12. Хан-Магомедов С.О. Лезгинское народное творчество. М.: Наука, 1969. 276 с.

13. Боциев Ю. Избранные произведения. Орджоникидзе, 1978. 254 с.

14. Илли. Героико-эпические песни чеченцев и ингушей. Грозный, 1979. 112 c.

15. Ошаев Х.Д. Некоторые вопросы использования нахских башен в бою. Тбилиси: Мецниереба, 1968. Т. 2. 376 с.

16. Крупнов Е.Н. Средневековая Ингушетия. М.: Наука, 1971. 356 с.

17. Блейх Н., Дзугаева М.. Содержание и система военно-физической подготовки юношества у северокавказских народов // Вопросы педагогики и психологии /Под ред. проф. Е.Е.Хатаева. Владикавказ: СОГУ, 2006. С. 17-23.

18. Марковин В.И. Дорогами и тропами Дагестана.-М.: Искусство, 1976. 312 с.

19. Клапрот Ю. Путешествие по Кавказу и Грузии, предпринятое в 1807-1808 гг. //Изв. СОНИИ. Вып. XII, 1948. С. 112

\section{References (transliterated):}

1. Ibn Ruste. Iz knigi dragotsennykh kamnei. Per. s arabskogo N.Karaulova //SMOMPK, № 32, 1903.-S. 42-47.

2. Pakhomov E.A. Krupneishie pamyatniki Sasanidskogo stroitel'stva v Zakavkaz'e //SA. № 8. 1946.-S. 13-19.

3. Kagankatvatsi M. Istoriya Agvan.-SPb., 1861. S. 15.

4. Lavrov L.I. Epigraficheskie pamyatniki Severnogo Kavkaza na arabskom, persidskom i turetskom yazykakh.-M., 1980. S. 74.

5. Kokiev G.A. Boevye bashni i zagraditel'nye steny gornoi Osetii //IYuONII.-Stalinir, 1935.-T. 2. S. 87.

6. Krupnov E.N. Srednevekovaya Ingushetiya.-M.: Nauka, 1971. S. 123.

7. Markovin V.I. Dorogami i tropami Dagestana.-M.: Iskusstvo, 1976. S. 243.

8. Urushadze N.E. K semantike prikladnogo iskusstva drevnego Kavkaza i Zakavkaz'ya //SA, 1979. № 1.-S. 54-70.

9. Miziev I.M. Chechenskie srednevekovye pamyatniki v verkhov'yakh r. Chanty-Arguna //Drevnosti Checheno-Ingushetii. M.:Nauka, 1963. $423 \mathrm{~s}$.

10. Muzhukhoev M.B. K istorii pozdnesrednevekovogo zodchestva Tsentral'nogo Kavkaza //Poseleniya i zhilishcha narodov Checheno-Ingushetii. Groznyi, 1984. $467 \mathrm{~s}$.

11. Gol'dshtein A.F. Bashni v gorakh.-M.: Sovetskii khudozhnik, 1977. 523 s.

12. Khan-Magomedov S.O. Lezginskoe narodnoe tvorchestvo. M.: Nauka, 1969. $276 \mathrm{~s}$.

13. Botsiev Yu. Izbrannye proizvedeniya. Ordzhonikidze, 1978. $254 \mathrm{~s}$.

14. Illi. Geroiko-epicheskie pesni chechentsev i ingushei. Groznyi, 1979. $112 \mathrm{s.}$

15. Oshaev Kh.D. Nekotorye voprosy ispol'zovaniya nakhskikh bashen v boyu. Tbilisi: Metsniereba, 1968. T. $2.376 \mathrm{~s}$.

16. Krupnov E.N. Srednevekovaya Ingushetiya. M.: Nauka, 1971. $356 \mathrm{s.}$

17. Bleikh N., Dzugaeva M.. Soderzhanie i sistema voenno-fizicheskoi podgotovki yunoshestva u severokavkazskikh narodov // Voprosy pedagogiki i psikhologii /Pod red. prof. E.E.Khataeva. Vladikavkaz: SOGU, 2006. S. 17-23.

18. Markovin V.I. Dorogami i tropami Dagestana.-M.: Iskusstvo, 1976. 312 s.

19. Klaprot Yu. Puteshestvie po Kavkazu i Gruzii, predprinyatoe v 1807-1808 gg. //Izv. SONII. Vyp. XII, 1948. S. 112 